\title{
GCU
}

Glasgow Caledonian

University

University for the Common Good

\section{Toward improving the World Health Organization fifth moment for hand hygiene in the prevention of cross-infection}

Price, Lesley; Roome, Karen; Ritchie, Lisa; Reilly, Jacqui; McIntyre, Jackie; Godwin, Jon; Bunyan, Donald

Published in:

American Journal of Infection Control

DOI:

10.1016/j.ajic.2015.12.017

Publication date:

2016

Document Version

Author accepted manuscript

Link to publication in ResearchOnline

Citation for published version (Harvard):

Price, L, Roome, K, Ritchie, L, Reilly, J, McIntyre, J, Godwin, J \& Bunyan, D 2016, 'Toward improving the World Health Organization fifth moment for hand hygiene in the prevention of cross-infection', American Journal of Infection Control, vol. 44, no. 6, pp. 631-635. https://doi.org/10.1016/j.ajic.2015.12.017

\section{General rights}

Copyright and moral rights for the publications made accessible in the public portal are retained by the authors and/or other copyright owners and it is a condition of accessing publications that users recognise and abide by the legal requirements associated with these rights.

Take down policy

If you believe that this document breaches copyright please view our takedown policy at https://edshare.gcu.ac.uk/id/eprint/5179 for details of how to contact us. 
Towards improving the World Health Organization '5th moment' for hand hygiene in the prevention of cross infection 


\section{Abstract}

Background: The World Health Organization recommend 5 moments for when hand hygiene should be performed. This research explores a number of explanatory hypotheses in order to inform future intervention development with regard to improving compliance with the $5^{\text {th }}$ moment.

Methods: A sequential mixed methods study was conducted using non-participant observation and survey with focus groups informing the development of the questionnaire. A total of 484 participants were observed and 410 returned a post-observation questionnaire giving a response rate of $85 \%$. Analysis explored the role of organisational culture, professional culture/practice and individual-level variables in explaining compliance with the $5^{\text {th }}$ moment.

Results: $93 \%$ of participants performed hand hygiene following the $5^{\text {th }}$ moment. Compliance varied between regions, but not professional group. Over $65 \%$ indicated that the $5^{\text {th }}$ moment was clearly defined, achievable, valuable, encouraged and widely known. However, $60 \%$ suggested that it was repetitive. There was a positive relationship between the performance of hand hygiene following the $5^{\text {th }}$ moment and the perception that it was widely known.

Conclusion: Interventions to improve compliance with the $5^{\text {th }}$ moment should focus on promoting awareness of the 5th moment and how it should be implemented in practice. Mechanisms for raising awareness should include education and role modelling.

Key Words: hand hygiene, $5^{\text {th }}$ moment, perceptions, healthcare staff, observation, questionnaire 


\section{Introduction}

Hand hygiene is considered to be one of the most effective measures in reducing and preventing the incidence of avoidable illness, in particular healthcare associated infections. ${ }^{1,2}$ Staff within health care settings should be aware of this and perform hand hygiene effectively and in a timely fashion. ${ }^{3,4}$ The World Health Organization's (WHO) ' 5 moments for hand hygiene' concept is supported by an evidence based hand transmission model and aims to provide reference points for care staff when hand hygiene should be performed in order to interrupt the transmission of microorganisms during delivery of care. ${ }^{4,5}$ This model has been adopted worldwide ${ }^{3}$ to provide direction and consistency across guidelines; and as a method of auditing hand hygiene practices.

There is consensus in the literature that hand hygiene should be performed:

- Before patient contact (moment 1$):{ }^{3 ; 6,7}$ Observational studies have demonstrated the risk of contamination of patients following contact with contaminated hands of healthcare staff. ${ }^{8-11}$ Systematic and non-systematic reviews describe the importance of performing hand hygiene before touching a patient mainly to prevent cross-colonization of the patient. ${ }^{5,12-16}$

- Before carrying out a clean/aseptic procedure (moment 2) such as handling an invasive device..$^{5-7,13,15-18}$ These procedures are considered high-risk and a maximum reduction in microbial counts on the hands is necessary. ${ }^{3}$

- Immediately after contact with body fluids, mucous membranes or wound dressings (moment 3$)^{5-7,13,15,16,18}$ Performing hand hygiene at this moment is necessary to reduce the risk of infection to healthcare staff, as microorganisms can be isolated from infected wounds, but also to reduce the risk of transfer of microorganisms from a colonized to a clean site during different care activities on the same patient. ${ }^{5,6,15}$

- Following contact with patients (moment 4$)^{8-11,19,20}$ similar to reasons stated above for moment 1.

- The 5th and final moment of the WHO hand hygiene guidelines is defined as "after touching patient surroundings on leaving the patient zone". In terms of the hospital environment the 
"patient zone" encompasses "...all inanimate surfaces that are touched by or in direct physical contact with the patient such as the bed rails, bedside table, bed linen, infusion tubing or other medical equipment" and "...surfaces frequently touched by healthcare workers while caring for the patient..."4

Whilst this theoretical rationale is supported by a number of studies that demonstrate that hands can become contaminated after contact with contaminated surfaces such as the patient's bed, bedside table or equipment within the patient's surroundings $s^{8 ; 9,11,21-23}$ there is still some confusion regarding the limits of the patient's immediate environment (patient zone) and the level of contact required, leading to a lack of clarity about how this key moment is defined and subsequently implemented in practice. Compliance data for all hand hygiene opportunities indicates variation in compliance between the 5 moments with moment 5 being the lowest ${ }^{24-25}$.

There is a need for evidence-based Interventions which enhance hand hygiene overall and equally for those which focus upon compliance with the $5^{\text {th }}$ moment alone. The current study used sequential mixed methods to explore the perceptions and behaviours of health care staff regarding compliance with the $5^{\text {th }}$ moment. Three broad hypotheses relating to variance within compliance are examined. Firstly that compliance relates to the local and organisational culture of hand hygiene (i.e. one region rather than another), secondly that compliance relates to professional culture of particular health professionals (e.g., doctors vs nurses) and finally that compliance relates to individual differences between participants (based upon their psychological beliefs).

\section{Methodology}

The research aim was to evaluate healthcare staff's perceptions of the WHO hand hygiene moment 5 relative to compliance with this moment.

The research questions were: 
1. Do healthcare staff comply with moment 5 in practice?

2. Does compliance vary between regions (as a reflection of local organisational culture)

3. Does compliance vary across the professional groups? (as a reflection of professional culture, role, training and practice)

4. Does compliance vary in relation to individual beliefs?

A mixed methods study was adopted, in cooperation with local members of the infection prevention and control teams, who conducted the observation and distributed the survey. Initially focus groups were held, by the researchers, with healthcare staff to explore their perceptions of the value of moment 5 in order to develop hypotheses for a self-report questionnaire to test with a larger sample of healthcare staff. Non-participant observation of healthcare staffs' compliance with the $5^{\text {th }}$ moment was conducted concurrently with the local hand hygiene audits. Following each observation the member of staff was asked to complete the questionnaire. Hence, data was collected of healthcare staff's actual behaviour in relation to, and their perceptions of, the $5^{\text {th }}$ moment.

Population and sample

The population was healthcare staff observed during local hand hygiene audits during 2013 . The purposive sample were any member of staff observed in hospitals in three different geographical areas of Scotland who had an opportunity to perform hand hygiene in accordance with the WHO $5^{\text {th }}$ moment.

\section{Recruitment}

Observation: The local infection prevention and control team emailed all staff prior to the hand hygiene audit informing them that in addition to collecting data for the local and national audit, they would be collecting data for a research study on hand hygiene compliance at the same time. 
Survey: During the audit if a member of staff was observed who had an opportunity to perform hand hygiene following moment 5 that member of staff was asked to complete a self-report questionnaire exploring their perceptions of the $5^{\text {th }}$ moment. Staff members were given an information sheet about the study and a questionnaire and were provided with an anonymous way of returning the completed questionnaire.

\section{Ethical considerations}

Approval to conduct the study was gained from Glasgow Caledonian University Ethics Committee and permission to access staff was gained from the hospitals involved. Participants' consent was implied by cooperation in the audit and return of the questionnaire. No personal identifying information was collected about the participants as they were identified solely by allocation of a unique participant number which also identified their hospital.

\section{Data collection}

Observation: Non-participant structured observation of 484 health care staff members was conducted to assess staff's compliance with moment 5 using an observational tool designed for the study. In addition to compliance with moment 5 data was collected on the context in which moment 5 was observed and the professional group of the participant. Piloting and refining of the tool was undertaken with the infection prevention and control teams involved in the study. In addition the tool was reviewed for content and face validity with infection control experts and the lay person on the Project Management Group.

Survey: Focus groups where conducted with a number of healthcare staff to ascertain their perceptions of the $5^{\text {th }}$ moment, findings were then used to develop the questionnaire. The questionnaire contained 8 semantic differential rating scales which were created from the most frequently cited adjectives used in the focus groups to describe the $5^{\text {th }}$ moment along with their polar adjectives. The use of constructs from the focus groups and the development of the 
questionnaire with the Project Management Group and piloting with healthcare staff ensured face and content validity.

Scoring of the survey: In order to quantify healthcare staffs' perceptions of moment 5 forced responses, using a five point scale, were used in the questionnaire. The possible scores ranged from 2 to 2 with the higher positive score representing a more favorable view.

\section{Data analysis}

Data analysis was conducted using SPSS ${ }^{\odot}$. Where appropriate Chi-squared, Mann-Whitney $\mathrm{U}$ and Kruskal-Wallis tests were employed. Significance was set at the $p<0.05$ was regarded as 'significant' in a single test, or with a Bonferroni correction $p<0.05 / n$ for $n$ tests. The latter is indicated with a double asterix $(* *)$.

\section{Results}

Of the 484 participants who were observed, 410 returned a questionnaire giving a response rate of $85 \%$. Of these, 404 could be matched to the observation. An indication of the representativeness of the sample was obtained by comparing the \% of staff in each professional group to data representative of the health service as a whole. There was a difference between the study sample and the national data as reflected by the significant Chi-square test for heterogeneity $\left(\chi^{2}{ }_{3}=9.4\right.$, $\left.1 p=0.02^{* *}\right)$. While the study sample was representative of the nurses, medical staff and allied health professionals in the health service, the ancillary staff were over represented $\left(\chi^{2}(1)=6.2,2 p=0.01^{* *}\right)$. In relation to research question 1 it was seen that overwhelmingly staff took appropriate action after touching the near patient environment (Table 1). Of 476 observations, 441 (93\%) performed hand hygiene; either washing their hands, using alcohol rub or both washing their hand and using alcohol rub, and only 35 (7\%) performed no hand hygiene. Crosstabs were performed to see if there was any difference in those who performed hand hygiene and those that did not according to professional group, region and the context in which the opportunity arose. Allied health professionals and 
ancillary staff groups had the higher proportions (96\%) of staff performing hand hygiene and medical staff the lowest (88\%) however this was not a significant difference as reflected in the heterogeneity test $\left(\chi^{2}{ }_{3}=5.3,1 p=0.2\right)$.

Table 1: Hand hygiene compliance and Professional group

\begin{tabular}{|l|r|r|r|}
\hline & $\begin{array}{l}\text { Performed hand } \\
\text { hygiene after the 5 } \\
\text { moment } \mathrm{n}(\%)\end{array}$ & $\begin{array}{l}\text { No hand hygiene } \\
\text { after the 5 } \\
\text { moment } \mathrm{n}(\%)\end{array}$ & 233 \\
\hline Nurses & $214(92 \%)$ & $79(8 \%)$ & 57 \\
\hline Medical staff & $50(88 \%)$ & $3(12 \%)$ & 104 \\
\hline Allied Health Professionals & $68(96 \%)$ & $4(4 \%)$ & $465^{*}$ \\
\hline Ancillary/Others & $100(96 \%)$ & $33(7 \%)$ & \\
\hline Total & $432(93 \%)$ & & \\
\hline
\end{tabular}

Heterogeneity $\chi^{2}{ }_{3}=5.3,1 p=0.2 \quad *$ Missing data 11

In relation to research question 2 there was a significant difference between geographical areas; indicative of organisational culture. Region three had the highest percentage of staff performing hand hygiene following the $5^{\text {th }}$ moment $(96 \%)$ followed by region two $(93 \%)$ and region one $(86 \%)$ $\left(\chi_{3}^{2}(2)=10.3,1 p=0.006^{* *}\right)$. When a Fisher's Exact test was performed to explore the nature of this difference this confirmed that region three had a greater percentage of staff performing hygiene appropriately than region one or two (Fisher's $2 p=0.01^{* *}$ ) and that region one had a lesser percentage of staff doing so compared to region two or three (Fisher's $2 p=0.006^{* *}$ ).

Overall staff perceptions of the $5^{\text {th }}$ moment were positive. The patterns of responses was similar with most participants considering that the $5^{\text {th }}$ moment was clearly defined ( $\left.\mathrm{n} 287,71 \%\right)$, achievable (n271, 67\%), essential (n313, 77\%) valuable (n311,76\%), encouraged (n283, 70\%) and widely known (n270, 67\%). The pattern of responses for how time consuming the $5^{\text {th }}$ moment was, were marginal with $56 \%$ (n228) of participants indicating that it was not too time consuming. However, this variable also had the highest percentage of responses in the middle of the scale (n107, 26\%) with participants 
neither expressing a view that it was or was not too time consuming. The pattern of responses in regard to the repetitive nature of the $5^{\text {th }}$ moment was the least positive with $59 \%$ (n239) of the participants expressing the view that the $5^{\text {th }}$ moment was repetitive. Overall the highest mean score was for the $5^{\text {th }}$ moment being essential and the lowest for it being repetitive (Table 2).

Table 2: Healthcare staffs' perceptions of moment 5

\begin{tabular}{|l|l|l|l|l|l|l|l|l|}
\hline Statistic & Defined & Achievable & Essential & Time & Encouraged & Valuable & Repetitive & Widely \\
known & & & & & & & & \\
\hline consuming & & & & & & & & \\
\hline number & 396 & 395 & 397 & 398 & 396 & 397 & 389 & 397 \\
\hline $\begin{array}{l}\text { standard } \\
\text { deviation }\end{array}$ & 1.056 & 1.221 & 1.084 & 1.300 & 1.162 & 1.117 & 1.281 & 1.172 \\
\hline
\end{tabular}

However the perceptions of the professional groups varied. To explore where the differences in perceptions between the groups was significance a t-test was performed. For each variable the groups with the lowest and highest mean scores were compared. Significant differences were found between ancillary staff and medical staff. Ancillary staff rated essential ( $\mu=1.56$ compared to 0.81 $\left.\mathrm{p}=<0.001^{* *}\right)$ and encouraged $\left(\mu=1.18\right.$ compared to $\left.0.42 \mathrm{p}=<0.001^{* *}\right)$ higher than medical staff.

In relation to research question 3 a Mann-Whitney $U$ test was performed to investigate whether or not compliance with moment 5 was associated with perceptions of moment 5 . The only significant variable was widely known. This showed that those who performed hand hygiene scored widely known higher than those who did not perform hand hygiene.

Following each observation observers were asked, where ever possible, to observe what the next opportunity for hand hygiene was. For the majority of participants the next moment after moment 5 was moment 1 (51\%). 


\section{Discussion}

Overall hand hygiene compliance following the $5^{\text {th }}$ moment was high (93\%) with staff taking the opportunity to perform hand hygiene. Although this is high, it is likely to be have been inflated by the presence of the researchers. Srigley et $\mathrm{al}^{26}$ identified that hand hygiene compliance was approximately threefold higher in eyesight of an auditor compared with when no auditor was visible.

Significant findings from this study show in what areas interventions to improve compliance with the $5^{\text {th }}$ moment could be developed. Firstly, findings from this study indicate that compliance with the $5^{\text {th }}$ moment varied according to region but not professional group suggesting that differences in local training, resources and environment are influencing compliance. This is indicative of the role of organisational culture in shaping hand hygiene and interventions to target local organisational culture are worthy of investment as supported by the findings of De Bone et al's ${ }^{27}$ literature review.

Secondly, individuals' beliefs about how widely known the 5th moment was, influenced compliance. Those who performed hand hygiene after moment 5 scored widely known higher compared to those who did not perform hand hygiene suggesting that interventions directed towards increasing staff's awareness of moment 5 would enhance compliance. Education may be used to raise awareness of the $5^{\text {th }}$ moment as a systematic review of interventions to improve hand hygiene compliance ${ }^{30}$ identified that there was a lack of robust evidence to support interventions but one study ${ }^{31}$ did show an increase in hand hygiene compliance with education. Furthermore for medical staff role modelling may be important in raising awareness as indicated by difference in individual beliefs between the professional groups in relation to the variables essential and encouraged. Ancillary staff thought the $5^{\text {th }}$ moment was essential and encouraged whilst medical staff were the least positive professional group about these aspects. The perception by medical staff that the $5^{\text {th }}$ moment was not encouraged may be one reason why their level of compliance is less than other professional groups as a positive role model has been shown to increase hand hygiene compliance. ${ }^{29}$ 
Findings from the study suggest that awareness raising also needs to be conducted in relation to the WHO's hand hygiene guidelines. Most participants were positive about the $5^{\text {th }}$ moment stating that it was clearly defined, achievable, essential, valuable, encouraged and widely known. However participants were less positive about the repetitive nature of the $5^{\text {th }}$ moment. Staff in the focus groups felt that they had to perform hand hygiene each time they touched a surface within the patient zone whereas the guidelines ${ }^{4}$ (p102) state that hand hygiene should "occurs after hand exposure to any surface in the patient zone, and before a subsequent hand exposure to any surface in the health-care area". As the guidelines ${ }^{4}$ explain that the "necessity for hand hygiene before touching objects within the patient zone is not supported by evidence", the $5^{\text {th }}$ moment should be conducted on leaving and not after each contact with surfaces in the patient zone. To be able to implement these guidelines effectively staff must understand them and be able to clearly differentiate between the patient and healthcare zone within every healthcare environment. Another reason why the $5^{\text {th }}$ moment may be perceived as repetitive is that the guidelines ${ }^{4}$ acknowledge that, at times, two of the five moments for hand hygiene could coincide; requiring hand hygiene to be performed only once. Staff may not be aware of this guidance as in this study the majority of staff went directly from performing hand hygiene after moment 5 to perform hand hygiene before the next opportunity, moment 1 , and therefore repeated hand hygiene unnecessaryily. ${ }^{4}$

Finally the current emphasis on hand hygiene education for all healthcare workers ${ }^{4}$ regardless of professional grouping may mean the professionals cultures of healthcare staff, in relation to hand hygiene practice, are becoming less diverse. Although a previous study ${ }^{28}$ found a significant difference between healthcare staff compliance with medical staff complying only $47 \%$ of the time, the difference in compliance across professional groups in our study was not significant.

It is acknowledge that the context in which this study took place could have confounded the findings. In particular it is relevant to note that that data collection occurred concurrently with data 
collection for the local audits. In addition that Scotland has had a national hand hygiene campaign since 2007 and a theoretical zero tolerance of non-compliance with hand hygiene standards since $2009 .{ }^{32}$ If anything these events would be expected to increase compliance.

\section{Conclusions}

Hand hygiene is considered one of the most effective measures in reducing and preventing healthcare associated infection. ${ }^{1,2}$ The WHO's ' 5 moments for hand hygiene' concept is supported by an evidence based hand transmission model and aims to provide reference points for healthcare staff when hand hygiene should be performed in order to interrupt the transmission of microorganisms during delivery of care. ${ }^{4,5}$

Intervention developments to target the local culture of hand hygiene and raise awareness of the $5^{\text {th }}$ moment are recommended. Education and role modelling should be used to raise awareness of and an in-depth understanding how the $5^{\text {th }}$ moment should be implemented in practice and used alongside moment 1. As these recommendations are based on empirical evidence of healthcare staff perceptions of hand hygiene practice, where compliance has been shown to be lowest, they provide guidance to the infection and prevention control team that should also improve overall hand hygiene compliance.

\section{Acknowledgments}

The authors acknowledge funding from the Scottish Infection Research Network that allowed the study to be conducted and acknowledge the following for help with data collection: Mary Ballentyne, Pauline Hamilton, Jacqueline McCallum, Lesley McNab, Val Ness, Christine Organ and Liz Simpson.

\section{References}


1. Johnson PD, Martin R, Burrell LJ, Grabsch EA, Kirsa SW, O'Keeffe J, et al. Efficacy of an alcohol/chlorhexidine hand hygiene program in a hospital with high rates of nosocomial methicillin-resistant Staphylococcus aureus (MRSA) infection. Med J Aust 2005;183(10): 509514.

2. Lepelletier D, Corvec S, Caillon J, Reynaud A, Roze JC, Gras-Leguen C. Eradication of methicillin-resistant Staphylococcus aureus in a neonatal intensive care unit: which measures for which success? Am J Infect Control 2009;37(3):195-200.

3. Larson EL. APIC guideline for handwashing and hand antisepsis in health care settings. Am J Infect Control 1995;23(4):251-69.

4. World Health Organization. WHO guidelines on hand hygiene in health care: first global patient safety challenge clean care is safer care. Geneva: WHO; 2009. http://whqlibdoc.who.int/publications/2009/9789241597906_eng.pdf

5. Sax H, Allegranzi B, Uckay I, Larson E., Boyce J, Pittet D. 'My five moments for hand hygiene': a user-centred design approach to understand, train, monitor and report hand hygiene. $J$ Hosp Infect 2007;67(1):9-21.

6. Boyce JM, Pittet D. Guideline for hand hygiene in health-care settings: recommendations of the Healthcare Infection Control Practices Advisory Committee and the HICPAC/SHEA/APIC/IDSA Hand Hygiene Task Force. Am J Infect Control 2002;30(8):S1-46.

7. Pittet D, Allegranzi B, Boyce J. The World Health Organization Guidelines on Hand Hygiene in Health Care and their consensus recommendations. Infect Control Hosp Epidemiol 2009;30(7):611-22.

8. Duckro AN, Blom DW, Lyle EA, Weinstein RA, Hayden MK. Transfer of vancomycin-resistant enterococci via health care worker hands. Arch Intern Med 2005;165(3):302-307.

9. Hayden MK, Blom DW, Lyle EA, Moore CG, Weinstein RA. Risk of hand or glove contamination after contact with patients colonized with vancomycin-resistant enterococcus or the colonized patients' environment. Infect Control Hosp Epidemiol 2008;29(2):149-154. 
10. Lam RF, Hui M, Leung DY, Chow VC, Lam BN, Leung GM, et al. Extent and predictors of microbial hand contamination in a tertiary care ophthalmic outpatient practice. Invest Ophthalmol Vis Sci 2005;46(10):3578-3583.

11. Pessoa-Silva CL, Dharan S, Hugonnet S, Touveneau S, Posfay-Barbe K, Pfister R, et al. Dynamics of bacterial hand contamination during routine neonatal care. Infect Control Hosp Epidemiol 2004;25(3):192-197.

12. Bibbolino C. Hygiene precautions and the transmission of infections in radiology. Radiologica Medica 2009;114(1):111-120.

13. Bjerke NB. The evolution: Handwashing to hand hygiene guidance. Crit Care Nurs Q 2004; 27(3):295-307.

14. Hart S. Using an aseptic technique to reduce the risk of infection. Nurs Stand 2007;21(47):43-48.

15. Pittet D, Allegranzi B, Sax H, Dharan S, Pessoa-Silva CL, Donaldson L, et al. Evidence-based model for hand transmission during patient care and the role of improved practices. Lancet Infect Dis 2006;6(10)641-652.

16. Pittet D. Hand hygiene: it's all about when and how(commentary). Infect Control Hosp Epidemiol 2008;29(10):957-959.

17. Hirschmann H, Fux L, Podusel J, Schindler K, Kundi M, Rotter M, et al.The influence of hand hygiene prior to insertion of peripheral venous catheters on the frequency of complications. J Hosp Infect 2001;49(3):199-203.

18. Loveday HP, Wilson JA, Pratt RJ, Golsorkhi M, Tingle A, Bak A et al. epic3: National Evidence-Based Guidelines for Preventing Healthcare-Associated Infections in NHS Hospitals in England. Journal of Hospital Infection (2014) 86S1: S1-S70.

19. Kac G, Podglajen I, Gueneret M, Vaupre S, Bissery A, Meyer G. Microbiological evaluation of two hand hygiene procedures achieved by healthcare workers during routine patient care: a randomized study. J Hosp Infect 2005;60(1):32-39. 
20. McBryde ES, Bradley LC, Whitby M , McElwain DL. An investigation of contact transmission of methicillin-resistant Staphylococcus aureus. J Hosp Infect 2004;58(2):104-108.

21. Bhalla A, Pultz NJ, Gries DM, Ray AJ, Eckstein EC, Aron DC, et al. Acquisition of nosocomial pathogens on hands after contact with environmental surfaces near hospitalized patients. Infect Control Hosp Epidemiol 2004;25(2):164-167.

22. Ray AJ, Hoyen CK, Taub TF, Eckstein EC, Donskey CJ. Nosocomial transmission of vancomycin-resistant enterococci from surfaces. JAMA 2002;287(11):1400-1401.

23. Grabsch EA, Burrell LJ, Padiglione A, O'Keeffe JM, Ballard S. Grayson ML. Risk of environmental and healthcare worker contamination with vancomycin-resistant enterococci during outpatient procedures and hemodialysis. Infect Control Hosp Epidemiol 2006;27(3):287-293.

24. Health Protection Scotland National Hand Hygiene NHS Campaign Compliance with Hand Hygiene - Audit Report 27th Bi-monthly Report (September 2013) http://www.hps.scot.nhs.uk/haiic/ic/nationalhandhygienecampaign.aspx\#twentyseventhbi( accessed 1st December 2014

25. Health \& Safety Executive Health Protection Surveillance Centre Report on Hand Hygiene Compliance in Acute Hospitals May/June 2013 Dublin http://www.hpsc.ie/AZ/Gastroenteric/Handwashing/HandHygieneAudit/HandHygieneAuditResults/PreviousReports/Fi le,14285,en.pdf accessed $4^{\text {th }}$ December 2015

26. Srigley JA, Furness CD, Baker GR, Gardam M. Quantification of the Hawthorne effect in hand hygiene compliance monitoring using an electronic monitoring system: a retrospective cohort study. BMJ Qual 2014;23(12):974-980. 
27. De Bono S, Heling G, Borg MA. Organizational culture and its implications for infection prevention and control in healthcare institutions. 2014;86(1):1-6.

28. Randle J, Arthur A, Vaughan N. Twenty-four-hour observational study of hospital hand hygiene compliance. J Hosp Infect 2010;76(3):252-255.

29. Erasmus V, Brouwer W, van Beeck EF, Oenema A, Daha TJ, Richardus JH, et al. Qualitative Exploration of Reasons for Poor Hand Hygiene Among Hospital Workers: Lack of Positive Role Models and of Convincing Evidence That Hand Hygiene Prevents Cross-Infection. Infect Control Hosp Epidemiol 2009;30(5):415-419.

30. Gould DJ, Moralejo D, Drey N, Chudleigh JH. Interventions to improve hand hygiene compliance in patient care (Review). The Cochrane Library 2010;9:

DOI: 10.1002/14651858.CD005186.pub3.http://www.tufts.edu/med/apua/consumers/resour ces 7 962926375.pdf (accessed 1st December 2014)

31. Huang J, Jiang D, Wang X, Liu Y, Fennie K, Burgess J, et al. Changing knowledge, behavior and practice related to universal precautions among hospital nurses in China. Journal of Continuing Education in Nursing 2002;33(5):217-24.

32. Martin P. Zero Tolerance to Non Hand Hygiene Compliance CEL 5. Edinburgh: The Scottish Government; 2009. 